\title{
EKONOMİK EMİSYON YÜK DAĞITIMI PROBLEMİ İÇİN KAOTİK YILDIRIM ARAMA ALGORITMASI
}

\author{
Serhat DUMAN ${ }^{*}$, Bayram YILDIZ²
}

${ }^{1}$ Düzce Üniversitesi, Teknoloji Fakültesi, Elektrik-Elektronik Mühendisliği Bölümü, Düzce, Türkiye 2Düzce Üniversitesi, Fen Bilimleri Enstitüsü, Bilgisayar Mühendisliği ABD, Düzce, Türkiye

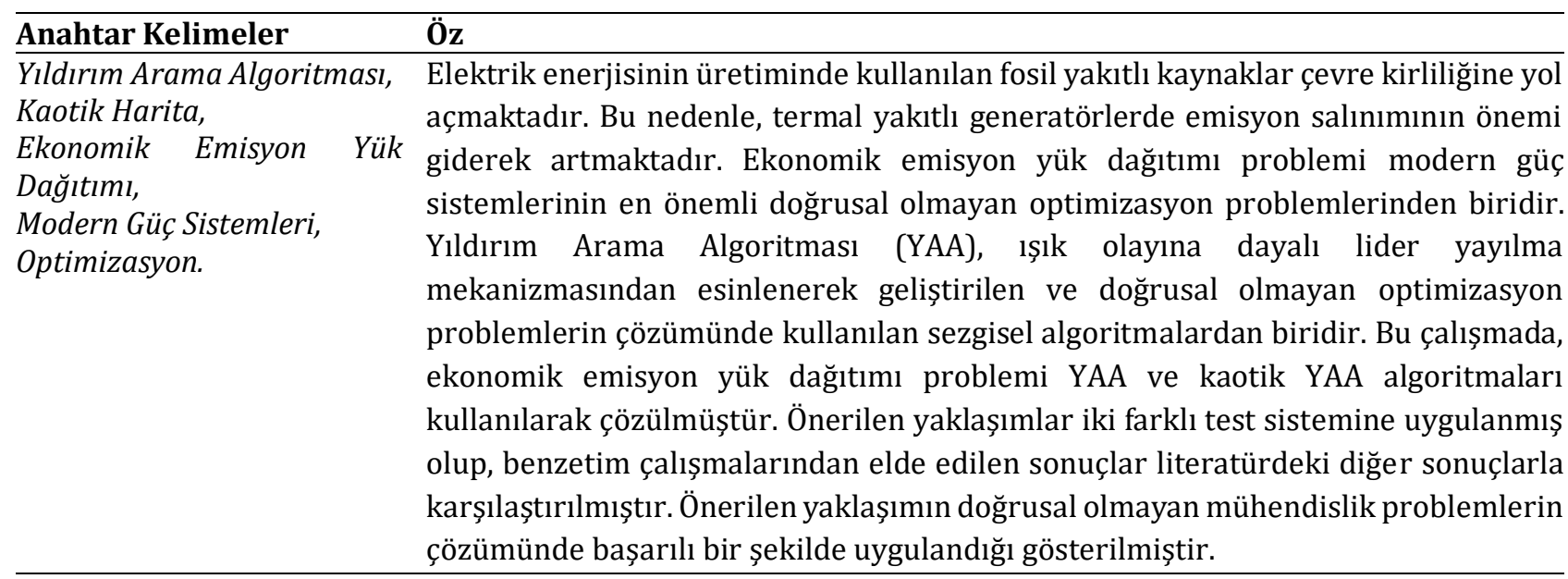

\section{CHAOTIC LIGHTNING SEARCH ALGORITHM FOR ECONOMIC EMISSION LOAD DISPATCH PROBLEM}

\begin{tabular}{ll}
\hline Keywords & Abstract \\
\hline $\begin{array}{l}\text { Lightning Search Algorithm, } \\
\text { Chaotic Map, }\end{array}$ & $\begin{array}{l}\text { The used fossil fuel sources in the production of electrical energy is lead to } \\
\text { environmental pollution. For this reason, importance of emission release in the } \\
\text { Economic Emission Load } \\
\text { thispatch, }\end{array}$ \\
$\begin{array}{l}\text { Modern Power Systems, } \\
\text { dispatch problem is one of the most important nonconvex optimization problems of } \\
\text { the modern power systems. Lightning Search Algorithm (LSA) is one of the heuristic } \\
\text { algorithms for solving nonconvex optimization problems and it is inspired from the } \\
\text { mechanism of step leader propagation and based on the phenomenon of lighting. In } \\
\text { this study, the economic-emission load dispatch problem is solved by using the LSA } \\
\text { and chaotic LSA algorithms. The proposed approaches are applied to the two } \\
\text { different test system and the obtained results from the simulation studies are } \\
\text { compared to the other results in the literature. The proposed approach is } \\
\text { successfully applied to solve the nonconvex engineering problems. }\end{array}$
\end{tabular}

\footnotetext{
Alıntı / Cite

Duman, S., Ylldız, B., (2018). Chaotic Lightning Search Algorithm For Economic Emission Load Dispatch Problem, Journal of Engineering Sciences and Design, 6(3), 406-417.
}

\begin{tabular}{l|l|l}
\hline Yazar Kimliği / Author ID (ORCID Number) & \multicolumn{3}{|l}{ Makale Süreci / Article Process } \\
\hline Serhat DUMAN, 0000-0002-1091-125X & Başvuru Tarihi /Submission Date & 26.03 .2018 \\
Bayram YILDIZ, 0000-0003-2029-0853 & Revizyon Tarihi / Revision Date & 05.04 .2018 \\
& Kabul Tarihi / Accepted Date & 26.07 .2018 \\
& Yayım Tarihi / Published Date & 11.09 .2018 \\
\hline
\end{tabular}

\footnotetext{
* ilgili yazar / Corresponding author: serhatduman@duzce.edu.tr
} 


\section{Giriş}

Modern güç sistemlerinin planlanması ve işletilmesinde en önemli planlama konularından biri olan ekonomik yük dağıtımı (EYD) doğrusal olmayan optimizasyon problemi olarak bilinmektedir. EYD problemi, termal yakıtlı elektrik üretim tesislerinde generatörlerin ürettikleri güçlere bağlı olarak yakıt maliyetinin asgari düzeyde tutulması olarak tanımlanmaktadır. Bu işlemi yaparken, generatörlerin belirtilen üretim sınır değerleri içerisinde kalması istenmekte olup, talep edilen güce göre generatörler arasında güç paylaşımının yapılması ve sistemdeki kayıp katsayı matrisinin göz önünde bulundurulması gerekmektedir. Başka bir ifadeyle, problem belirtilen eşitlik ve eşitsizlik kısıtları içerisinde yakıt maliyetinin en asgari düzeye indirilmesi olarak da ifade edilebilir. $\mathrm{Bu}$ problem, araştırmacılar tarafından ilk olarak ele alındığında geleneksel yaklaşımlardan lineer programlama, kuadratik programlama ve doğrusal olmayan programlama teknikleri ile çözülmeye çalışılmıştır (Fraq vd., 1995; Nabora ve Freris, 1973; Lin vd., 1992; Chen ve Chen, 2003). Son ylllarda geleneksel yaklaşımlara bir alternatif olarak sezgisel optimizasyon algoritmaları kullanılmaya başlanmıştır (Kavousi-Fard ve Khosravi, 2016; Duman vd., 2015; Meng vd., 2016; Secui, 2015).

Bahrani ve Patra eylemsizlik katsayılı global parçacık sürü optimizasyonu kullanarak farklı sınırlar altında büyük güçlü termal üretim birimlerinin yakıt maliyetini en asgari düzeye indirmeye çalışmışlardır. Yazarlar önerdikleri algoritmayı, farklı test sistemlerine uygulamışlar elde ettikleri sonuçları literatürdeki diğer sezgisel yaklaşımlarla karşılaştırmışlardır. Elde edilen benzetim sonuçlarına göre, önerdikleri yaklaşımın çok boyutlu konveks olmayan böyle problemlerin çözümünde etkili olduğunu belirtmişlerdir (Bahrani ve Patra, 2018). Kheshti ve ark. şimşek arama algoritmasını dalga nokta etkili ve çoklu yakıt planlamasını içeren amaç fonksiyonlarının minimum değerini bulmada kullanmayı amaçlamışlardır. Önerilen algoritma 10, $40,80,160$ ve 640 üretim birimini içeren test sistemlerine uygulanmış olup, kullanılan amaç fonksiyonları için en uygun çözümü bulma ve çözüme hızlı yakınsamasıyla diğer algoritmalara göre daha etkin olduğu yazarlar tarafından belirtilmiştir (Kheshti vd., 2017). Naderi ve ark. önerdikleri bulanık mantık temelli hibrit parçacık sürü optimizasyonu ve diferansiyel evrim algoritmasinı farklı test sistemlerinde farklı amaç fonksiyonlarını kullanarak performansını test etmişlerdir. Benzetim sonuçlarına göre, önerilen yaklaşımdan elde edilen sonuçlar literatürdeki diğer sezgisel algoritmalardan elde edilen sonuçlar göre daha etkin olduğu yazarlar tarafından belirtilmiştir (Naderi vd., 2017).

Ayrıca, kömür, petrol ve doğal gaz gibi fosil kaynaklı yakıtları kullanan elektrik üretim tesislerinde, nitrojen oksit $\left(\mathrm{NO}_{\mathrm{x}}\right)$, sülfür dioksit $\left(\mathrm{SO}_{\mathrm{x}}\right)$ ve karbondioksit $\left(\mathrm{CO}_{2}\right)$ gibi atmosfere zarar veren gazların ortama salınması, çevresel kirliliğe neden olmasının yanı sıra küresel ısınmaya da sebebiyet vermektedir (Basu, 2014; Shilaja ve Ravi, 2017). Emisyon etkileri ve çevresel etkenlerde göz önünde bulundurulduğunda, ekonomik yük dağıtımı problemi çok amaçlı bir optimizasyon problemi olarak modern güç sistemlerinde yerini almaktadır. Çok amaçlı optimizasyon problemi olan ekonomik emisyon yük dağıtım problemi ağırlıklı toplam yöntemi kullanılarak tek amaçlı optimizasyon problemine döndürülür (Aydın vd., 2014; Mason vd., 2017). Qu ve ark. çoklu amaç fonksiyonu kullanılarak modellenmiş çevresel/ekonomik yük dağıtımı problemlerinde kullanılan sezgisel algoritmalara yönelik bir araştırma çalışması yapmışlardır. Yapmış oldukları bu çalışma kapsamında, bu problemin çözümünde kullanılan test sistemleri, sezgisel algoritmalar, amaç fonksiyonları, eşitlik ve eşitsizlik sınırları detaylı bir şeklide verilerek, modern güç sistemlerinde kullanılan dinamiklerinde probleme eklenerek çalıșılması gerektiğini belirtmişlerdir (Qu vd., 2018).

Zou ve ark. yeni global parçacık sürü optimizasyon algoritmasını güç sistemlerinin planlama problemlerinden ekonomik emisyon yük dağıtımı problemine uygulamışlardır. Yazarlar, beş farklı test sistemi için önerdikleri sezgisel yaklaşım ile minimum toplam yakıt maliyeti ve emisyon salınımını elde etmeyi amaçlamışlardır. Çalışmalarında, ekonomik yük dağıtımı ve emisyon salınımı ayrı ayrı tekil amaç fonksiyonu olarak düşünülmüş olup, bu amaç fonksiyonlarının birleștirilmiş hali de çoklu amaç fonksiyonu olarak kullanılmıştır. Elde edilen sonuçlar, literatürdeki diğer optimizasyon algoritmalarından elde edilen sonuçlar ile karşılaștırılmış ve önerilen yaklaşımın güç sistemlerindeki ekonomik emisyon problemini çözmedeki başarısı sunulmuştur (Zou vd., 2017). Bu güç sistemi planlama problemi literatürde çoklu popülasyon temelli karınca kolonisi (Zhou vd., 2017), gerçek kodlu kimyasal reaksiyon algoritması (Bhattacharjee vd., 2014), ateş böceği algoritması (Younes vd., 2014), iyileștirilmiş bakteri yem arama algoritması (Pandit vd., 2012), Zit konumlu harmoni arama algoritması (Chatterjee vd. 2012), bulanık mantığa dayalı parçacık sürü optimizasyonu ve yerçekimsel arama algoritması (Duman vd., 2015), su döngüsü algoritması (Elhameed ve El-Fergany, 2017), ortogonal parçacık sürü algoritması (Bahrani ve Patra, 2017) gibi farklı sezgisel algoritmalar kullanılarak araştırmacılar tarafından ele alınmıştır.

Son ylllarda popülasyon temelli algoritmalardan biri olan ve yıldırımın toprağa inmesi doğa olayından esinlenerek Shareef ve ark. (Shareef vd., 2014) tarafından geliştirilen Yıldırım Arama Algoritması (YAA) bir çok mühendislik optimizasyon problemlerine uygulanmıştır. Bu çalışmada, Yıldız ve ark. (Yıldız vd., 2017) tarafindan literatüre sunulan Kaotik Yıldırım Arama Algoritmasının (KYAA) modern güç sistemlerinin optimizasyon problemlerinden biri olan ekonomik emisyon yük dağıtımı problemine uygulanması sunulmuştur. Benzetim çalışmaları 
sonucunda önerilen yaklaşımdan elde edilen sonuçlar literatürdeki diğer sonuçlarla karşılaştırılmış olup, karşılaştırma sonuçları göz önünde bulundurulduğunda önerilen kaotik yıldırım arama algoritmasının doğrusal olmayan ekonomik emisyon yük dağıtımı problemini çözmedeki başarısı değerlendirilmiştir.

$\mathrm{Bu}$ çalışma, ikinci bölümde ekonomik emisyon yük dağıtımı probleminin tanımlanması, üçüncü bölümde kaotik yıldırım arama algoritması, benzetim sonuçları dördüncü bölümde, beşinci bölümde ise sonuçlar olacak şekilde düzenlenmiştir.

\section{Ekonomik Emisyon Yük Dağıtımı Problemi}

Ekonomik emisyon yük dağıtımı problemi, termal yakıtlı elektrik üretim birimlerinde yakıt maliyeti ve atmosfere salınan emisyon miktarının birleştirilmiş amaç fonksiyonu olarak minimize edilmesi şeklinde ifade edilebilir. Diğer bir deyişle, termal yakıtlı üretim birimlerinin bağlı olduğu güç sistemlerinde talep edilen yükü karşılamak için üretim birimlerinde fosil yakıtların kullanılmasıyla atmosfere salınan zararlı emisyon miktarının ve toplam yakıt maliyetinin asgari düzeyde olduğu anda belirlenen eşitlik ve eşitsizlik sınırları içerisinde generatörlerin aktif güç değerlerinin belirlenmesi olarak da tanımlanabilir. Güç sistemlerindeki termal yakıtlı generatörlerin toplam yakıt maliyeti, Denklem (1)'deki ikinci dereceden fonksiyonda generatörlerin üreteceği güçlerin yerine konması ile oluşan amaç fonksiyonu olarak ifade edilir (Duman vd., 2015; Aydin vd., 2014; Bhattacharjee vd., 2014; Basu, 2014).

$$
F_{i}\left(P_{G i}\right)=a_{i}+b_{i} P_{G i}+c_{i} P_{G i}^{2}
$$

Burada, $F_{i}\left(P_{G i}\right) \quad i$. generatörün yakıt maliyeti fonksiyonu, $P_{G i} i$. generatörün ürettiği güç değeri, $a_{i}, b_{i}$, $c_{i} i$. generatörün yakıt maliyeti katsayılarıdır. Ayrıca, Denklem (2)'deki gibi valf nokta etkisi dahil edilerek toplam yakıt maliyeti fonksiyonu doğrusal olmayan daha yüksek bileşenlere sahip güç sistemi planlama problemine dönüştürülür.

$$
\begin{aligned}
& F_{i}\left(P_{G i}\right)=a_{i}+b_{i} P_{G i}+c_{i} P_{G i}^{2}+ \\
& \left|d_{i} \times \sin \left(e_{i} \times\left(P_{G i}^{\min }-P_{G i}\right)\right)\right|
\end{aligned}
$$

Denklem (2)'de $d_{i}$ ve $e_{i} i$. generatörün maliyet fonksiyonu katsayıları, $P_{G i} \min$ ise $i$. generatörün üretebileceği en düşük aktif güç değeri olarak tanımlanır. Termal yakıtlı elektrik üretim santrallerinde fosil yakıtların kullanılması ile her bir güç üretim birimi tarafından salınan zararlı gazların toplam miktarı Denklem (3)'deki gibi ifade edilmektedir (Qu vd., 2018; Aydin vd., 2014; Zhou vd., 2017).

$$
\mathrm{E}_{\mathrm{i}}\left(\mathrm{P}_{\mathrm{Gi}}\right)=\left(\alpha_{\mathrm{i}}+\beta_{\mathrm{i}} \mathrm{P}_{\mathrm{Gi}}+\gamma_{\mathrm{i}} \mathrm{P}_{\mathrm{Gi}}^{2}\right)+\left(\zeta_{\mathrm{i}} \exp \left(\mathrm{P}_{\mathrm{Gi}} \lambda_{\mathrm{i}}\right)\right)
$$

Ekonomik, ekonomik-emisyon yük dağıtım problemlerinde, güç sistemi kayıpsız veya kayıplı olarak düşünülürse aktif güç dengesi eşitliği Denklem (4) ve (5)'te gösterildiği gibi ifade edilir.

$$
\begin{aligned}
& \sum_{i=1}^{N} P_{G i}-P_{\text {yük }}=0 \quad, \forall i \in N \\
& \sum_{i=1}^{N} P_{G i}-P_{\text {yïk }}-P_{\text {kayip }}=0 \quad, \forall_{i} \in N
\end{aligned}
$$

$N$ toplam generatör sayısını, $P_{\text {kayip }}$ sistemin toplam aktif güç kaybını, $P_{y u ̈ k}$ sistemin toplam talep edilen aktif güç değerini ifade etmektedir. Güç sisteminin toplam aktif güç kaybı Denklem (6)'da, generatörlerin sınır değerleri ise Denklem (7)'de gösterilmiştir.

$$
\begin{aligned}
& P_{\text {kayip }}=\sum_{i=1}^{N} \sum_{j=1}^{N} P_{G i} B_{i j} P_{G j}+\sum_{i=1}^{N} B_{0 i} P_{G i}+B_{00} \\
& P_{G i}^{\min } \leq P_{G i} \leq P_{G i}^{\max }
\end{aligned}
$$

$\mathrm{Bu}$ çalışmada salınım barasına ait generatörün hesaplanması aktif güç dengesi eşitliğinden yararlanılarak Denklem (8)'de sunulmuştur.

$P_{N}=P_{y \ddot{i k}}+P_{\text {kayip }}-\sum_{i=1}^{(N-1)} P_{G i}$

Salınım barasına ait generatör ve diğer generatör ünitelerini içeren $P_{\text {kayip }}$ denkleminin matematiksel ifadesi Denklem (9)'da gösterilmektedir.

$$
\begin{aligned}
P_{\text {kayip }}= & \sum_{i=1}^{N-1} \sum_{j=1}^{N-1} P_{G i} B_{i j} P_{G j}+2 P_{N}\left(\sum_{i=1}^{N-1} B_{N i} P_{G i}\right)+ \\
& B_{N N} P_{N}^{2}+\sum_{i=1}^{N-1} B_{0 i} P_{G i}+B_{0 N} P_{N}+B_{00}
\end{aligned}
$$

Güç dengesi eşitliği yeniden düzenlenirse Denklem (10) elde edilir.

$$
\begin{aligned}
& B_{N N} P_{N}^{2}+\left(2 \sum_{i=1}^{N-1} B_{N i} P_{G i}+B_{0 N}-1\right) P_{N}+ \\
& \left(\begin{array}{l}
P_{y \ddot{i} k}+\sum_{i=1}^{N-1} \sum_{j=1}^{N-1} P_{G i} B_{i j} P_{G j}+\sum_{i=1}^{N-1} B_{0 i} P_{G i}- \\
\sum_{i=1}^{N-1} P_{G i}+B_{00}
\end{array}\right)=0
\end{aligned}
$$

Denklem (10), aşağıdaki denklem formuna dönüştürülerek denklemin pozitif kökü bize salınım barasına ait generatörün değerini vermektedir.

$$
X P_{N}^{2}+Y P_{N}+Z=0
$$




$$
\begin{aligned}
& X=B_{N N} \\
& Y=\left(2 \sum_{i=1}^{N-1} B_{N i} P_{G i}+B_{0 N}-1\right) \\
& Z=\left(\begin{array}{l}
P_{y \ddot{i} k}+\sum_{i=1}^{N-1} \sum_{j=1}^{N-1} P_{G i} B_{i j} P_{G j}+\sum_{i=1}^{N-1} B_{0 i} P_{G i}- \\
\sum_{i=1}^{N-1} P_{G i}+B_{00}
\end{array}\right. \\
& P_{N}=\frac{-Y \pm \sqrt{Y^{2}-4 X Z}}{2 X} \\
& Y^{2}-4 X Z \geq 0
\end{aligned}
$$

Ekonomik emisyon yük dağıtımına ait uygunluk fonksiyonu Denklem (14)'te ifade edilmektedir.

$$
A F=w \times \sum_{i=1}^{N} F_{i}\left(P_{G i}\right)+(1-w) \times \varepsilon \times\left(\sum_{i=1}^{N} E_{i}\left(P_{G i}\right)\right)(14)
$$

Termal yakıtlı generatörlerin yakıt maliyeti $F_{i}\left(P_{G i}\right)$, termal yakitlı generatörlere ait emisyon fonksiyonu ise $E_{i}\left(P_{G i}\right)$ ile ifade edilmektedir. $w 0$ ile 1 arasında değișen ağırlık faktörü, $\varepsilon$ ölçekleme faktörü olup, Denklem (14)'te $w^{\prime}$ nin 1 değerini alması sadece generatör ünitelerinin yakıt maliyetini, $w^{\prime}$ nin 0 değerini alması ise sadece generatör ünitelerinin emisyon miktarının minimumun olduğu duruma karşıllk gelen uygunluk fonksiyonunu ifade etmektedir.

\section{Yıldırım Arama Algoritması}

Yıldırım Arama Algoritması (YAA) yıldırımın toprağa inmesi doğa olayından esinlenerek Shareef ve ark. (Shareef vd., 2014) geliştirilen son ylllardaki popülasyon temelli optimizasyon algoritmalarından biridir. Algoritma üç ana kısımdan oluşmaktadır.

\subsection{Roket ve Adım Lideri Yayılımı}

YAA'da gök gürültüsü doğa olayı göz önünde bulundurularak, gök gürültüsü hücresinden her bir roketin bir adım lideri ve bir kanal oluşturduğu varsayılmaktadır. Başka bir ifadeyle, roket belirtilen sınır değerleri içerisinde başlangıçtaki popülasyonun boyutunu temsil etmekte olup, optimizasyon probleminin çözümü için rasgele çözümler önermektedir (Shareef vd., 2014).

\subsection{Roketlerin Özellikleri}

Normal koşullar altında atmosferde dolaşan bir roket, havadaki moleküller ve atomlarla yaptığı esnek çarpışmalar sırasında kinetik enerjisini kaybetmekte buna bağlı olarak, roketin hızı Denklem (15)'e göre ifade edilir (Shareef vd., 2014).

$v_{p}=\left[1-\left(1 / \sqrt{1-\left(v_{0} / c\right)^{2}}-s F_{i} / m c^{2}\right)^{-2}\right]^{-1 / 2}$

$v_{p}$ ve $v_{0}$ roketin şuandaki ve başlangıç hızları, $c$ ışığın hızl, $F_{i}$ sabit iyonizasyon oranı, $m$ roketin kütlesi olarak tanımlanmaktadır. Denklem (15), roketin kütlesi ve lider uç pozisyonunun bir fonksiyonu olarak ifade edilmektedir. Ayrıca YAA'nın en uygun noktayı araştırma özellikleri adım liderinin enerjileri ile tanımlanmaktadır (Shareef vd., 2014).

\subsection{Roket Modellemesi ve Adım Liderinin Hareketi}

$\mathrm{Bu}$ algoritmada, geçiş roketi, konum roketi ve öncü roketi olmak üzere üç roket türü tanımlanmaktadır. Burada, geçiş roketi ilk adım liderinin (N) popülasyonunu, uzay roketleri en iyi lider konuma ulaşmaya çalışanı ve öncü roketi ise $\mathrm{N}$ sayıda adım lideri arasından en iyi konuma sahip olanı ifade etmektedirler (Shareef vd., 2014)..

\section{Geçiş Roketi:}

Bu bölümde, gök gürültüsü hücresinden rastgele bir geçiş roketi firlatılmak üzere bir lider uç oluşturulur. Bu yüzden, düzgün olasılık dağılımının matematiksel ifadesi, rasgele sayıdaki lider ipucu modelini oluşturmak için kullanılmaktadır. Düzgün olasılık dağılımı aşağıdaki gibi tanımlanabilir (Shareef vd., 2014):

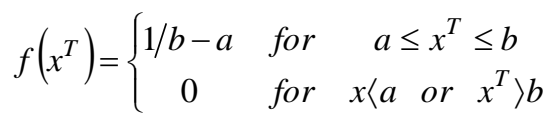

$s l_{i}$ adım liderinin başlangıç uç enerjisini $\left(E_{s L} i\right)$ ve bir çözümü sağlayan rasgele sayı $X^{T}$ olarak tanımlanır. $a$ ve $b$ çözüm uzayının minimum ve maksimum sınır değerleri şeklinde ifade edilir. $S L=\left[s l_{1}, s l_{2}, \ldots, s l_{N}\right], N$ adet adım liderinin popülasyonu, $P^{T}=\left\lfloor p_{1}^{T}, p_{2}^{T}, \ldots, p_{N}^{T}\right\rfloor$ $N$ adet rasgele roket olarak gösterilir (Shareef vd., 2014).

\section{Uzay Roketi:}

$\mathrm{Bu}$ bölümde uzay roketlerinin bir sonraki adım için pozisyonu $P^{S}=\left\lfloor p_{1}^{S}, p_{2}^{S}, \ldots, p_{N}^{S}\right\rfloor, \quad \mu$ biçimlendirme parametresi kullanılarak üstel dağılımdan üretilen rasgele bir sayı olarak ifade edilir (Shareef vd., 2014).

$$
f\left(x^{S}\right)=\left\{\begin{array}{ccc}
\frac{1}{\mu} e^{\frac{-x^{S}}{\mu}} & \text { for } & x^{S} \geq 0 \\
0 & \text { for } & x^{S} \leq 0
\end{array}\right.
$$

$\mu$ biçimlendirme parametresi bir sonraki iterasyonda yönü veya uzay roketinin pozisyonunu kontrol etmek 
için kullanılır. Bir sonraki adımda $p_{i}^{S^{\prime}}$ nin pozisyonu Denklem (18)'deki gibi ifade edilir (Shareef vd., 2014).

$p_{i_{-} \text {new }}^{S}=p_{i}^{S} \pm \operatorname{exprand}\left(\mu_{i}\right)$

$p_{i}^{S}$ new ve $p_{i}^{S}$ yeni ve eski roketleri ifade ederken, exprand üstel rasgele sayıyı temsil eder.

\section{Öncü Roketi:}

$\mathrm{Bu}$ bölümde öncü roketi, normal dağılım ifadesi ile biçim $(\mu)$ ve ölçeklendirme $(\sigma)$ parametreleri kullanılarak üretilen rasgele sayı olarak tanımlanır. Normal olasılık yoğunluk fonksiyonu aşağıdaki matematiksel ifade ile gösterilir (Shareef vd., 2014).

$$
f\left(x^{L}\right)=\frac{1}{\sigma \sqrt{2 \pi}} e^{-\left(x^{L}-\mu\right)^{2} / 2 \sigma^{2}}
$$

Ölçeklendirme parametresi en iyi çözüme doğru üssel olarak azalmaktadır. Bir sonraki adımda $p^{L}$ nin pozisyonu Denklem (20)'deki gibi ifade edilir (Shareef vd., 2014).

$p_{\text {new }}^{L}=p^{L}+$ normrand $\left(\mu_{L}, \sigma_{L}\right)$

$p^{L}$ ve $p^{L}{ }_{\text {new }}$ eski ve yeni öncü roketlerini ifade ederken, normrand dağılım fonksiyonu tarafından üretilen rasgele sayıyı temsil eder (Shareef vd., 2014). YAA'nın akıș diyagramı Şekil 1'de gösterilmiștir.

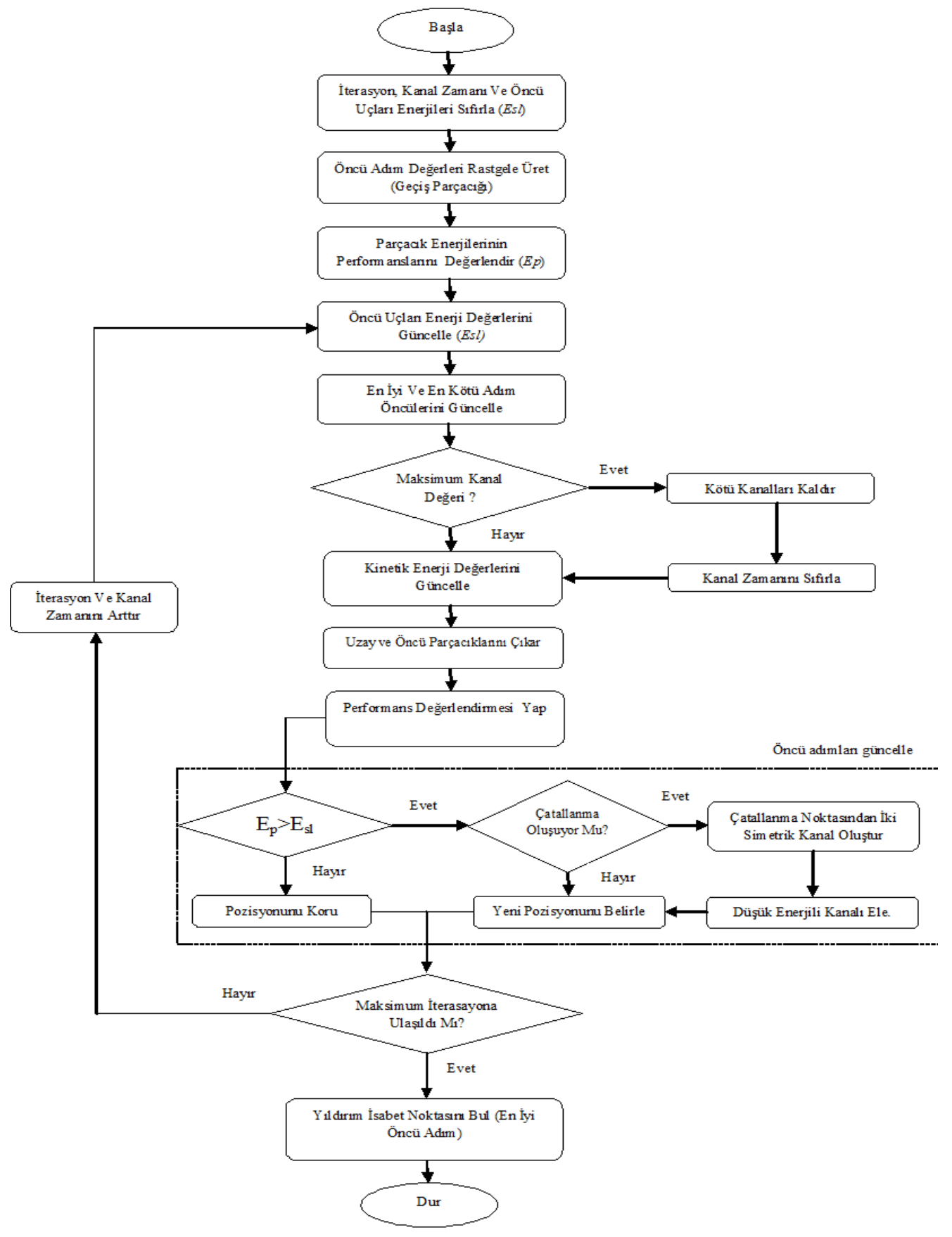

Şekil 1. Yıldırım arama algoritmasının akış diyagramı 


\subsection{Kaotik Yıldırım Arama Algoritması}

Başlangıç koşullarına son derece hassas ve gürültü gibi geniş güç aralığına sahip olan kaos, düzensizlik sırasına göre ifade edilebilir. Kaos, bilimsel anlamda ilk kez astronomi çalışmalarında karmaşık bir sistemin kararlılı̆̆ı üzerine kullanılmasına karşın, son yıllarda birçok araştırmacı tarafından farklı bilimsel çalışmalarda da kullanılmıştır (Bingöl vd., 2017; Pamuk, 2013). Optimizasyon algoritmaları incelendiğinde, rasgele sayı dizileri hemen hemen hepsinde kullanılmaktadır. Rasgele üretilen sayılar optimizasyon süresince kendilerini tekrar etme veya birbirlerine yakın değerler alması algoritmaların yerel minimum ya da maksimum değerleri bulmasına neden olabilir. Bu dezavantajı ortadan kaldırmak için kaotik haritalandırma yöntemleri kullanılmaktadır (Tanyıldızı ve Cigal, 2017). Alatas ve ark. kaotik haritaları kullanarak parçacık sürü optimizasyonu amaçlamıșlar (Alatas vd., 2009), Yang ve ark. kaos optimizasyon algoritmasını (Yang vd., 2014), Alatas kaotik harmoni arama algoritmasını (Alatas, 2010), Gandomi ve Yang kaotik yarasa algoritmasını (Gandomi ve Yang, 2014) Mirjalili ve Gandomi kaotik yerçekimi arama algoritmasını (Mirjalili ve Gandomi, 2017), literatüre sunmuşlardır. $\mathrm{Bu}$ çalışmada, optimizasyon algoritmasının en iyi çözüme doğru hareket etmesini sağlayan ölçeklendirme parametresi Mirjalili ve Gandomi tarafından literatüre sunulan kaotik haritalandırma yöntemi kullanılarak Şekil 2'deki gibi kaotik ölçeklendirme parametresi elde edilmiş, algoritmanın yerel minimum veya maksimuma takılma dezavantajı ortadan kaldırılmaya çalışılmıştır.
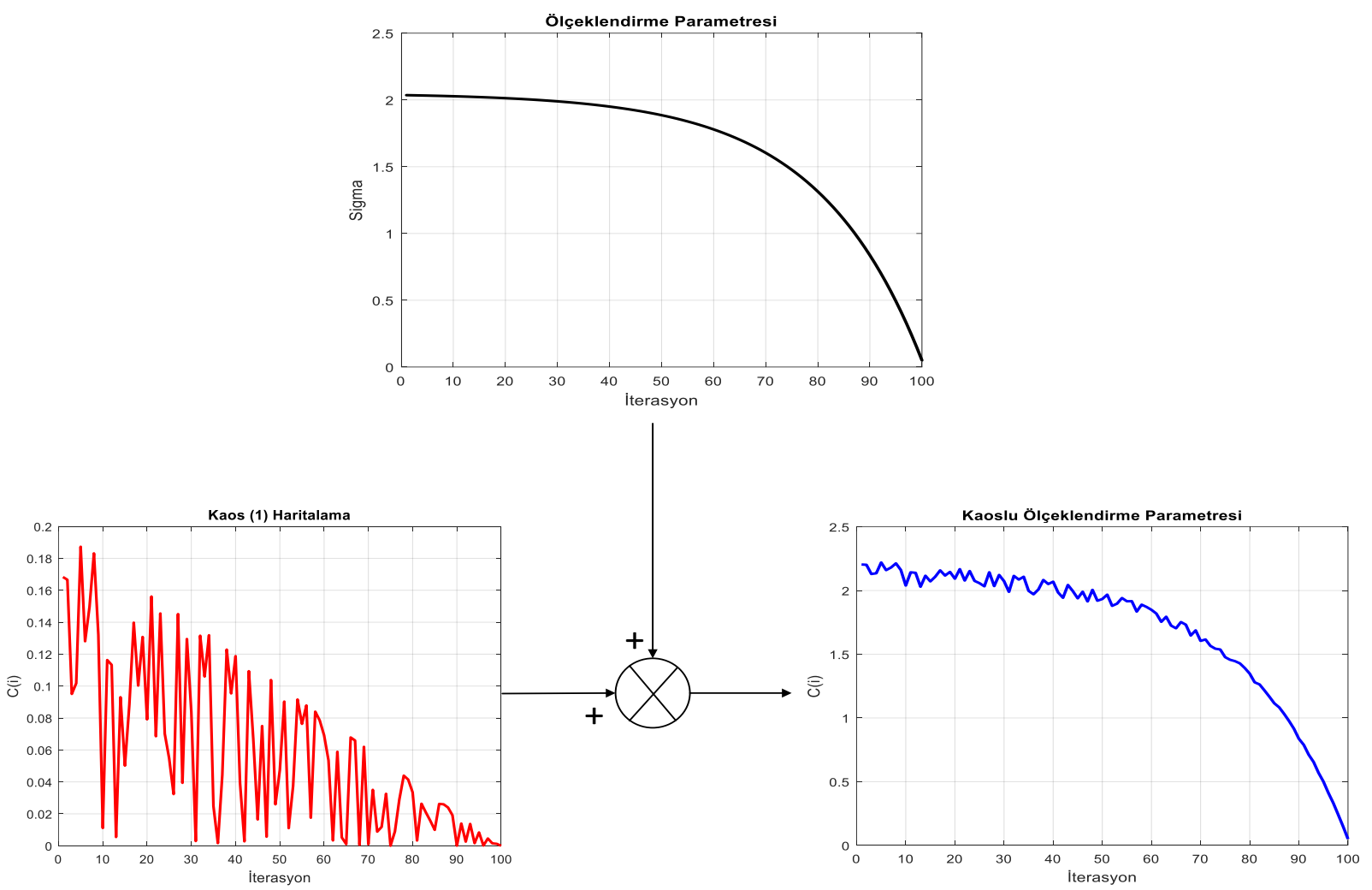

Şekil 2. Kaoslu ölçeklendirme parametresi

Tablo 1. Kaotik harita denklemleri

\begin{tabular}{|l|l|}
\hline Harita Adı & Fonksiyon \\
\hline Chebyshev (Kaos (1)) & $\mathrm{x}_{\mathrm{i}+1}=\cos \left(\mathrm{i} \cos ^{-1}\left(\mathrm{x}_{\mathrm{i}}\right)\right)$ \\
\hline $\begin{array}{l}\text { Circle (Kaos (2)) } \\
\mathrm{x}_{\mathrm{i}+1}=\bmod \left(\mathrm{x}_{\mathrm{i}}+\mathrm{b}-\left(\frac{\alpha}{2 \pi}\right) \sin \left(2 \pi \mathrm{x}_{\mathrm{i}}\right), 1\right) \\
\begin{array}{l}\text { Gauss/Mouse } \\
\text { (Kaos (3)) }\end{array}\end{array}$ & $\mathrm{x}_{\mathrm{i}+1}=\left\{\begin{array}{c}1 \\
\frac{1}{\bmod \left(\mathrm{x}_{\mathrm{i}}, 1\right)}\end{array} \quad\right.$ otherwise \\
\hline Iterative (Kaos (4)) & $\mathrm{x}_{\mathrm{i}+1}=\sin \left(\frac{\alpha \pi}{\mathrm{x}_{\mathrm{i}}}\right) \quad \mathrm{a}=0.7$ \\
\hline
\end{tabular}




\section{Benzetim Sonuçları}

$\mathrm{Bu}$ çalışmada, farklı yakıt maliyeti ve emisyon katsayılarına sahip iki test sistemi algoritmanın performansını değerlendirmek için düşünülmüştür. Tüm test durumları için Tablo 1'de verilen kaotik haritalar kullanılmış olup ekonomik emisyon yük dağıtımı problemini çözmedeki performansları değerlendirilmiştir.

\section{Test Sistemi 1}

Önerilen Kaotik Yıldırım Arama Algoritması (KYAA), 6 generatörlü, iletim hattı kayıplarının ihmal edilmediği ve 283.4 MW'lı yük talebini karşılarken, minimum yakıt maliyetini elde edebilmek için ekonomik yük dağıtımı problemine uygulanmıştır. Test sistemine ait veriler (Malik vd., 2010; Yaşar ve Özyön, 2011; Duman vd., 2015) referanslarından elde edilmiştir. Önerilen algoritma, bu test sistemi için 30 kez çalıştırılmış, elde edilen minimum, ortalama ve maksimum yakıt maliyeti değerleri Tablo 2'de gösterilmiștir.
Tablo 2. 6 Generatörlü sistemin sonuçları (Test 1)

\begin{tabular}{|c|c|c|c|}
\hline Yöntem & Min. & Ort. & Maks. \\
\hline YAA & 925.4154 & 932.9568 & 963.0069 \\
\hline K1YAA & 925.4158 & 935.4442 & 962.9992 \\
\hline K2YAA & 925.4147 & 936.707 & 963.0008 \\
\hline K3YAA & 925.4143 & 934.1951 & 963.0209 \\
\hline K4YAA & 925.4146 & 935.4579 & 963.0028 \\
\hline
\end{tabular}

Tablo 2'den de görüldüğü gibi, 30 deneme sonunda Kaos 3 olarak isimlendirilmiş (Gauss/Mouse) haritalandırma yöntemi ile en iyi sonuç bulunmuştur. K3YAA'dan elde edilen sonuç, literatürdeki diğer optimizasyon algoritmalarından elde edilen sonuçlarla karşılaştırıldığında GA, GA-APO, NSOA, PSO ve MSG-HP algoritmalarından daha iyi sonuç bulduğu, FPSOGSA ve SOS algoritmalarından 0.0006 \$ h daha fazla sonuç bulduğu görülmüștür. Test sistemi 1 için, önerilen kaotik haritalandırmalı yıldırım arama algoritmalarından elde edilen minimum toplam yakıt maliyetlerinin yakınsama eğrileri Şekil 3(a)'da gösterilmektedir. Şekil 3(a) detaylı bir şekilde incelendiğinde önerilen algoritma yaklaşık olarak 70'inci iterasyondan sonra minimum değere yakınsadığl görülmektedir.

Tablo 3. Önerilen K3YAA ve diğer optimizasyon algoritmalarından elde edilen sonuçların karşlaștırılması (Test sistemi 1)

\begin{tabular}{|c|c|c|c|c|c|c|c|c|}
\hline \multirow[b]{2}{*}{ Generatörler } & \multicolumn{8}{|c|}{ Yöntemler } \\
\hline & $\begin{array}{c}\text { GA } \\
\text { (Malik vd., } \\
\text { 2010) }\end{array}$ & $\begin{array}{c}\text { GA-APO } \\
\text { (Malik vd., } \\
\text { 2010) }\end{array}$ & $\begin{array}{c}\text { NSOA } \\
\text { (Malik vd., } \\
\text { 2010) }\end{array}$ & $\begin{array}{c}\text { PSO } \\
\text { (Yaşar ve } \\
\text { Özyön, } \\
\text { 2011) }\end{array}$ & $\begin{array}{c}\text { MSG-HP } \\
\text { (Yaşar ve } \\
\text { Özyön, } \\
\text { 2011) }\end{array}$ & $\begin{array}{l}\text { FPSOGSA } \\
\text { (Duman vd., } \\
\text { 2015) }\end{array}$ & $\begin{array}{c}\text { SOS } \\
\text { (Guvenc } \\
\text { vd., } \\
\text { Baskıda) }\end{array}$ & K3YAA \\
\hline $\mathrm{P}_{\mathrm{G} 1}$ & 150.724 & 133.9816 & 182.478 & 197.8648 & 199.6331 & 199.5997 & 199.5997 & 199.5997 \\
\hline $\mathrm{P}_{\mathrm{G} 2}$ & 60.8707 & 37.2158 & 48.3525 & 50.3374 & 20.0000 & 20.0000 & 20.0000 & 20.0000 \\
\hline $\mathrm{P}_{\mathrm{G} 3}$ & 30.8965 & 37.7677 & 19.8553 & 15.0000 & 23.7624 & 23.9896 & 23.9768 & 23.9626 \\
\hline $\mathrm{P}_{\mathrm{G}_{4}}$ & 14.2138 & 28.3492 & 17.1370 & 10.0000 & 18.3934 & 18.8493 & 18.8679 & 18.8063 \\
\hline $\mathrm{P}_{\mathrm{G} 5}$ & 19.4888 & 18.7929 & 13.6677 & 10.0000 & 17.1018 & 18.2153 & 18.2212 & 18.1726 \\
\hline $\mathrm{P}_{\mathrm{G} 6}$ & 15.9154 & 38.0525 & 12.3487 & 12.0000 & 15.6922 & 13.8506 & 13.8402 & 13.9666 \\
\hline Toplam Güç (MW) & 292.1096 & 294.1600 & 293.8395 & 295.2022 & 294.5829 & 294.5045 & 294.5058 & 294.5078 \\
\hline $\begin{array}{c}\text { Yakıt Maliyeti } \\
(\$ / \mathrm{h})\end{array}$ & 996.0369 & 1101.491 & 984.9365 & 925.7581 & 925.6406 & 925.4137 & 925.4137 & 925.4143 \\
\hline Kayıр (MW) & 8.7060 & 10.7563 & 10.4395 & 11.8022 & 11.1830 & 11.1044 & 11.1058 & $\mathbf{1 1 . 1 0 7 8}$ \\
\hline
\end{tabular}

\section{Test Sistemi 2}

Önerilen algoritma, IEEE 6 generatörlü 30 baralı ekonomik ve emisyon yük dağıtım problemine 2.834 pu yük talebiyle iletim hattı kayıplarının ihmal edilmediği, ihmal edilmesi durumunda, yakıt maliyetinin valf nokta etkili ve valf nokta etkisiz koşulları altında $30 \mathrm{kez}$ çalıștırılmış ve elde edilen minimum, ortalama ve maksimum değerleri Tablo 4 ve Tablo 5'de gösterilmiştir. Denklem (14)'te gösterilen amaç fonksiyonuna göre $w=1.0$ olduğu durumda sistemin toplam yakıt maliyeti, $w=0.0$ olduğu durumda ise toplam emisyon değeri hesaplanmaktadır. Ekonomik ve emisyon yük dağıtımı probleminin çözümünde kullanılan kaotik haritalandırılmış yıldırım arama algoritmasının iterasyon sayısı 100 olarak alınmıştır. Tablo 6'da sistem ilk olarak valf nokta etkisi ve kayıplı olarak düşünülmüş olup, sisteme ait generatör verileri, kayıp matrisi (Hemamalini ve Simon, 2008) referansından alınmıştır. Önerilen yaklaşımdan elde edilen sonuç literatürdeki PSO algoritmasından elde edilen sonuçtan 13.6213 \$/h daha azdır. Test sistemi 2 için, önerilen algoritmadan elde edilen minimum toplam valf nokta etkili yakıt maliyeti yakınsama eğrileri Şekil 3(b)'de gösterilmektedir.

Tablo 4. 6 Generatörlü valf nokta etkili sistemin sonuçları (Test sistemi 2)

\begin{tabular}{|c|c|c|c|}
\hline Yöntem & Min. & Ort. & Maks. \\
\hline YAA & 614.2507 & 618.0967 & 630.0553 \\
\hline K1YAA & 613.8961 & 616.7009 & 630.2594 \\
\hline K2YAA & 613.3961 & 616.874 & 630.9807 \\
\hline K3YAA & 613.3387 & 616.3131 & 622.2219 \\
\hline K4YAA & 613.3500 & 617.0027 & 627.3591 \\
\hline
\end{tabular}

Tablo 5. 6 Generatörlü valf nokta etkisiz sistemin sonuçları (Test sistemi 2)

\begin{tabular}{|c|c|c|c|}
\hline Yöntem & Min. & Ort. & Maks. \\
\hline YAA & 600.1145 & 600.1278 & 600.1598 \\
\hline K1YAA & 600.1134 & 600.1269 & 600.1715 \\
\hline K2YAA & 600.1125 & 600.1259 & 600.1523 \\
\hline K3YAA & 600.11 & 600.1223 & 600.1455 \\
\hline K4YAA & 600.114 & 600.1274 & 600.1835 \\
\hline
\end{tabular}




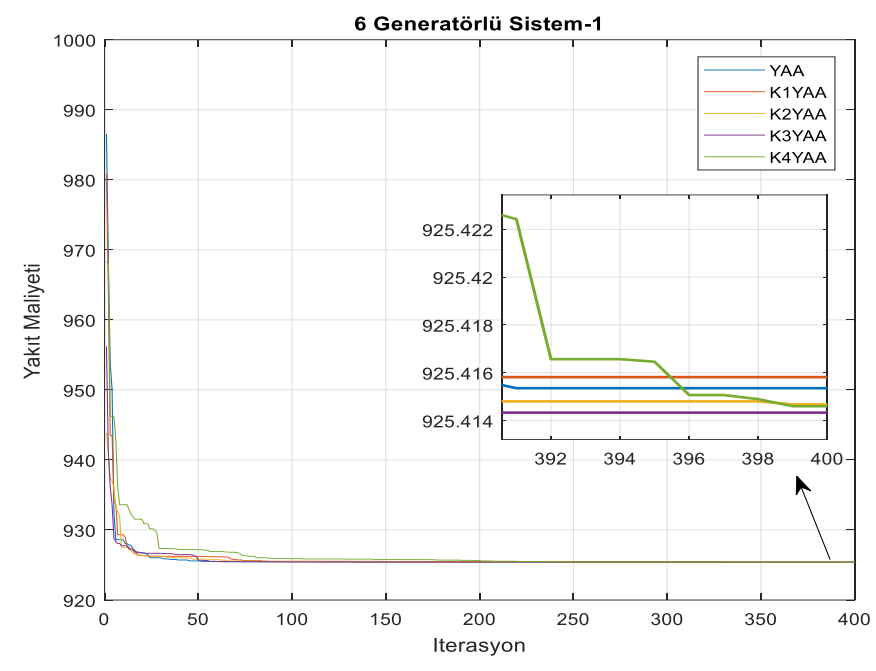

(a)

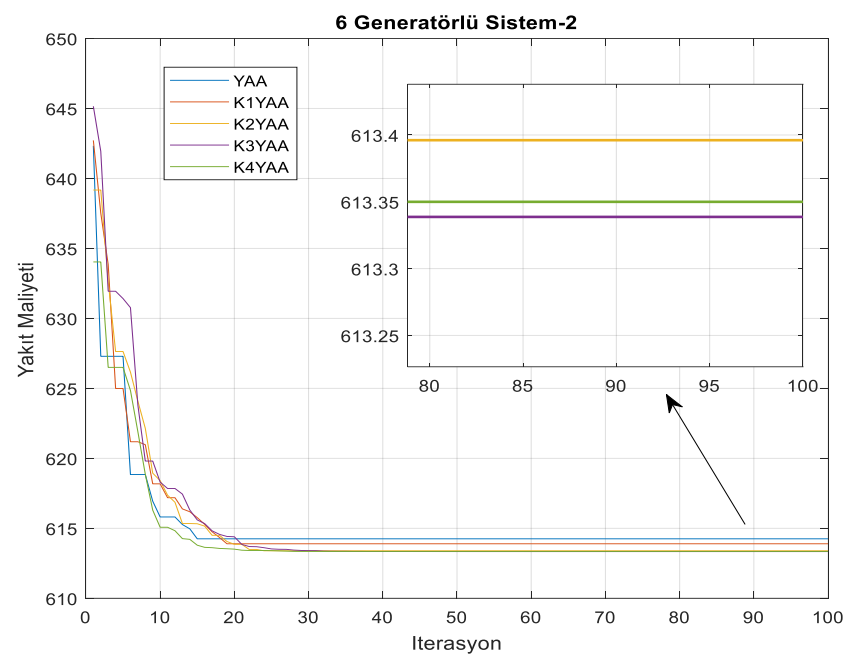

(b)

Şekil 3. Yakıt maliyeti yakınsama eğrisi 6 generatörlü sistem (a)Test sistemi 1 (b) Test sistemi 2 (Valf nokta etkili)

Tablo 6. Yakıt maliyeti minimizasyonu için optimizasyon algoritmalarından elde edilen sonuçların karşılaştırılması (Test sistemi 2)

\begin{tabular}{|c|c|c|c|c|c|c|c|c|c|c|}
\hline \multicolumn{11}{|c|}{ Valf Nokta Etkili ve kayıplı } \\
\hline Yöntem & $\mathbf{P}_{\mathrm{G} 1}$ & $\mathbf{P}_{\mathrm{G} 2}$ & $\mathbf{P}_{\mathrm{G} 3}$ & $\mathbf{P}_{\mathrm{G} 4}$ & $\mathbf{P}_{\mathrm{G} 5}$ & $\mathbf{P}_{\mathrm{G} 6}$ & $\begin{array}{l}\text { Toplam } \\
\text { Güç (pu) }\end{array}$ & $\begin{array}{c}\text { Yakit } \\
\text { Maliyeti } \\
(\$ / \mathbf{h})\end{array}$ & $\begin{array}{l}\text { Kayıр } \\
\text { (pu) }\end{array}$ & $\begin{array}{c}\text { Emisyon } \\
\text { (ton/h) }\end{array}$ \\
\hline $\begin{array}{c}\text { PSO } \\
\text { (Hemamalini } \\
\text { ve Simon, } \\
2008) \\
\end{array}$ & 0.099441 & 0.36248 & 0.48349 & 0.87359 & 0.66428 & 0.39004 & 2.873321 & 626.96 & 0.039321 & 0.21392 \\
\hline K3YAA & 0.05000 & 0.4000 & 0.6875 & 0.9500 & 0.5500 & 0.2310 & 2.8685 & 613.3387 & 0.03445 & 0.22337 \\
\hline \multicolumn{11}{|c|}{ Valf Nokta Etkisiz ve kayıpsız } \\
\hline $\begin{array}{l}\text { NSGA } \\
\text { (Abido, } \\
2006)\end{array}$ & 0.1038 & 0.3228 & 0.5123 & 1.0387 & 0.5324 & 0.3241 & 2.8341 & 600.34 & - & 0.2241 \\
\hline $\begin{array}{l}\text { NPGA } \\
\text { (Abido, } \\
2006 \text { ) }\end{array}$ & 0.1116 & 0.3153 & 0.5419 & 1.0415 & 0.4726 & 0.3512 & 2.8341 & 600.31 & - & 0.2238 \\
\hline $\begin{array}{c}\text { SPEA } \\
\text { (Abido, } \\
\text { 2006) }\end{array}$ & 0.1009 & 0.3186 & 0.5400 & 0.9903 & 0.5336 & 0.3507 & 2.8341 & 600.22 & - & 0.2206 \\
\hline $\begin{array}{l}\text { MBFA (Hota } \\
\text { vd., 2010) }\end{array}$ & 0.1133 & 0.3005 & 0.5202 & 0.9882 & 0.5409 & 0.3709 & 2.834 & 600.17 & - & 0.2200 \\
\hline $\begin{array}{c}\text { NSGA-II } \\
\text { (Zhang vd., } \\
\text { 2012) }\end{array}$ & 0.1059 & 0.3177 & 0.5216 & 1.0146 & 0.5159 & 0.3583 & 2.834 & 600.155 & - & 0.2219 \\
\hline $\begin{array}{l}\text { BB-MOPSO } \\
\text { (Zhang vd., } \\
\text { 2012) }\end{array}$ & 0.1090 & 0.3005 & 0.5234 & 1.0170 & 0.5238 & 0.3603 & 2.834 & 600.112 & - & 0.2222 \\
\hline $\begin{array}{c}\mathrm{DE} \\
\text { (Guerrero ve } \\
\text { Maldonado, } \\
\text { 2005) } \\
\end{array}$ & 0.110 & 0.300 & 0.524 & 1.016 & 0.524 & 0.360 & 2.834 & 600.11 & - & 0.2231 \\
\hline $\begin{array}{c}\text { OHS } \\
\text { (Chatterjee } \\
\text { vd., 2012) } \\
\end{array}$ & 0.1086 & 0.2995 & 0.5315 & 1.0121 & 0.5230 & 0.3591 & 2.8338 & 600.00 & - & 0.2219 \\
\hline $\begin{array}{l}\text { PSO (Jiang } \\
\text { vd., 2014) }\end{array}$ & 0.1066 & 0.2996 & 0.5243 & 1.0164 & 0.5262 & 0.3609 & 2.834 & 600.11 & - & 0.2223 \\
\hline $\begin{array}{l}\text { GSA (Jiang } \\
\text { vd., 2014) }\end{array}$ & 0.0947 & 0.2650 & 0.5418 & 0.9819 & 0.5070 & 0.4435 & 2.8339 & 601.06 & - & 0.2204 \\
\hline $\begin{array}{c}\text { HPSO-GSA } \\
\text { (Jiang vd., } \\
2014 \text { ) }\end{array}$ & 0.1096 & 0.2998 & 0.5243 & 1.0162 & 0.5243 & 0.3598 & 2.834 & 600.11 & - & 0.2221 \\
\hline $\begin{array}{c}\text { IYYAA } \\
\text { (Duman vd., } \\
2014 \text { ) }\end{array}$ & 0.1096 & 0.3000 & 0.5240 & 1.0163 & 0.5243 & 0.3598 & 2.834 & 600.11 & - & 0.22215 \\
\hline K3YAA & 0.1102 & 0.3022 & 0.5243 & 1.0161 & 0.5221 & 0.3591 & 2.834 & 600.11 & - & 0.22208 \\
\hline
\end{tabular}


Şekil 3(b) detaylı bir şekilde incelendiğinde önerilen algoritma yaklaşık olarak 30'uncu iterasyondan sonra minimum değere yakınsadığı görülmektedir. Tablo 6'da, ikinci olarak sistem valf nokta etkisiz ve kayıpsız olarak düşünülmüş olup, sisteme ait generatör verileri (Chatterjee vd., 2012) referansından alınmıştır. Önerilen yaklaşımdan elde edilen sonucun, karşılaştırılan optimizasyon algoritmalarından elde edilen sonuçlara benzer olduğu görülmüştür. Tablo 7'de sistem ilk olarak valf nokta etkisi ve kayıplı olarak düşünülmüş olup, minimum emisyon değeri elde edilmiștir. Önerilen yaklașımdan elde edilen sonuç literatürdeki PSO algoritmasından elde edilen sonuçtan 0.00144 ton $/ \mathrm{h}$ daha az olduğu ifade edilebilir.
Test sistemi 2 için, önerilen algoritmadan elde edilen minimum toplam valf nokta etkisiz yakıt maliyeti yakınsama eğrileri Şekil 4(a)'da gösterilmektedir. Şekil 4(a) detaylı bir şekilde incelendiğinde önerilen algoritma yaklaşık olarak 60'ıncı iterasyondan sonra minimum değere yakınsadığı görülmektedir. Test sistemi 2 için valf nokta etkisiz ve kayıpsız olarak 30 deneme yapılarak, önerilen algoritma ile emisyon salınımının en aza indirgeme benzetim çalışmaları yapılmıştır. Benzetim çalışmaları sonucunda elde edilen sonuçlar, literatürden elde edilen sonuçlarla karşılaștırıldığında en son elde edilen sonuçlara uygun sonuçlar olduğu Tablo 7'de gösterilmiştir. Şekil 4(b)'de valf nokta etkisiz ve kayıpsız sistem koşulları altında önerilen algoritma ile emisyon değerinin yakınsama eğrileri gösterilmektedir.

Tablo 7. Minimum emisyon için optimizasyon algoritmalarından elde edilen sonuçların karşılaştırılması (Test sistemi 2)

\begin{tabular}{|c|c|c|c|c|c|c|c|c|c|c|}
\hline \multicolumn{11}{|c|}{ Valf Nokta Etkili ve kayıplı (Emisyon) } \\
\hline Yöntem & $P_{G 1}$ & $\mathbf{P}_{\mathrm{G} 2}$ & $\mathbf{P}_{\mathrm{G} 3}$ & $P_{G 4}$ & $\mathbf{P}_{\mathrm{G} 5}$ & $\mathbf{P}_{\mathrm{G} 6}$ & $\begin{array}{l}\text { Toplam } \\
\text { Güç (pu) }\end{array}$ & $\begin{array}{c}\text { Yakıt } \\
\text { Maliyeti } \\
(\$ / \mathbf{h})\end{array}$ & $\begin{array}{c}\text { Kayıр } \\
\text { (pu) }\end{array}$ & $\begin{array}{c}\text { Emisyo } \\
n \\
\text { (ton/h) } \\
\end{array}$ \\
\hline $\begin{array}{c}\text { PSO } \\
\text { (Hemamalin } \\
\text { i ve Simon, } \\
\text { 2008) } \\
\end{array}$ & 0.37883 & 0.39323 & 0.49948 & 0.53439 & 0.57341 & 0.48651 & 2.86585 & 659.44 & $\begin{array}{c}0.0318 \\
5\end{array}$ & 0.19567 \\
\hline K3YAA & 0.3923 & 0.4700 & 0.5278 & 0.4008 & 0.5536 & 0.5229 & 2.8674 & $\begin{array}{c}677.859 \\
7\end{array}$ & 0.0334 & 0.19423 \\
\hline \multicolumn{11}{|c|}{ Valf Nokta Etkisiz ve kayıpsız } \\
\hline $\begin{array}{l}\text { NSGA } \\
\text { (Abido, } \\
2006 \text { ) }\end{array}$ & 0.4072 & 0.4536 & 0.4888 & 0.4302 & 0.5836 & 0.4707 & 2.8341 & 633.83 & - & 0.1946 \\
\hline $\begin{array}{l}\text { NPGA } \\
\text { (Abido, } \\
2006 \text { ) }\end{array}$ & 0.4146 & 0.4419 & 0.5411 & 0.4067 & 0.5318 & 0.4979 & 2.834 & 636.04 & - & 0.1943 \\
\hline $\begin{array}{c}\text { SPEA } \\
\text { (Abido, } \\
\text { 2006) } \\
\end{array}$ & 0.4240 & 0.4577 & 0.5301 & 0.3721 & 0.5311 & 0.5190 & 2.834 & 640.42 & - & 0.1942 \\
\hline $\begin{array}{l}\text { MBFA (Hota } \\
\text { vd., 2010) }\end{array}$ & 0.3943 & 0.4627 & 0.5423 & 0.3946 & 0.5346 & 0.5056 & 2.8341 & 636.73 & - & 0.1942 \\
\hline $\begin{array}{c}\text { NSGA-II } \\
\text { (Zhang vd., } \\
\text { 2012) }\end{array}$ & 0.4074 & 0.4577 & 0.5389 & 0.3837 & 0.5352 & 0.5110 & 2.8339 & 638.249 & - & 0.1942 \\
\hline $\begin{array}{l}\text { BB-MOPSO } \\
\text { (Zhang vd., } \\
\text { 2012) }\end{array}$ & 0.4071 & 0.4591 & 0.5374 & 0.3838 & 0.5369 & 0.5098 & 2.8341 & 638.262 & - & 0.1942 \\
\hline $\begin{array}{c}\text { DE } \\
\text { (Guerrero } \\
\text { ve } \\
\text { Maldonado, } \\
\text { 2005) } \\
\end{array}$ & 0.406 & 0.459 & 0.538 & 0.383 & 0.538 & 0.510 & 2.834 & 638.27 & - & 0.1952 \\
\hline $\begin{array}{c}\text { OHS } \\
\text { (Chatterjee } \\
\text { vd., 2012) } \\
\end{array}$ & $\begin{array}{c}0.41211 \\
6\end{array}$ & $\begin{array}{c}0.46694 \\
9\end{array}$ & $\begin{array}{c}0.54745 \\
4\end{array}$ & $\begin{array}{c}0.371177 \\
1\end{array}$ & $\begin{array}{c}0.53469 \\
3\end{array}$ & $\begin{array}{c}0.50101 \\
6\end{array}$ & $\begin{array}{c}2.83399 \\
9\end{array}$ & 639.5493 & - & 0.1942 \\
\hline $\begin{array}{l}\text { PSO (Jiang } \\
\text { vd., 2014) }\end{array}$ & 0.4017 & 0.4604 & 0.5403 & 0.3875 & 0.5360 & 0.5081 & 2.834 & 637.67 & - & 0.1942 \\
\hline $\begin{array}{l}\text { GSA (Jiang } \\
\text { vd., 2014) }\end{array}$ & 0.5000 & 0.5643 & 0.4435 & 0.4429 & 0.4818 & 0.4014 & 2.8339 & 643.96 & - & 0.1969 \\
\hline $\begin{array}{c}\text { HPSO-GSA } \\
\text { (Jiang vd., } \\
2014 \text { ) } \\
\end{array}$ & 0.4062 & 0.4591 & 0.5379 & 0.3829 & 0.5379 & 0.5100 & 2.834 & 638.27 & - & 0.1942 \\
\hline $\begin{array}{c}\text { IYAA } \\
\text { (Duman vd., } \\
2014 \text { ) }\end{array}$ & 0.4097 & 0.4563 & 0.5244 & 0.3930 & 0.5310 & 0.5196 & 2.834 & 637.9112 & - & 0.1942 \\
\hline K3YAA & 0.4004 & 0.4578 & 0.5268 & 0.3723 & 0.5551 & 0.5216 & 2.834 & 639.093 & - & 0.1942 \\
\hline
\end{tabular}




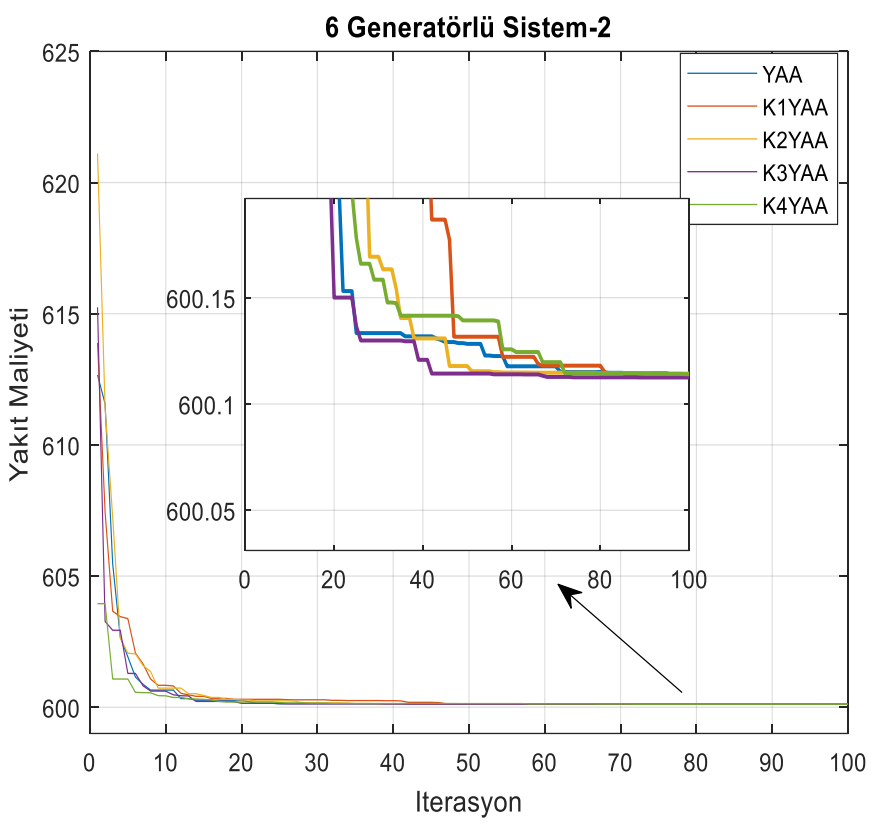

(a)

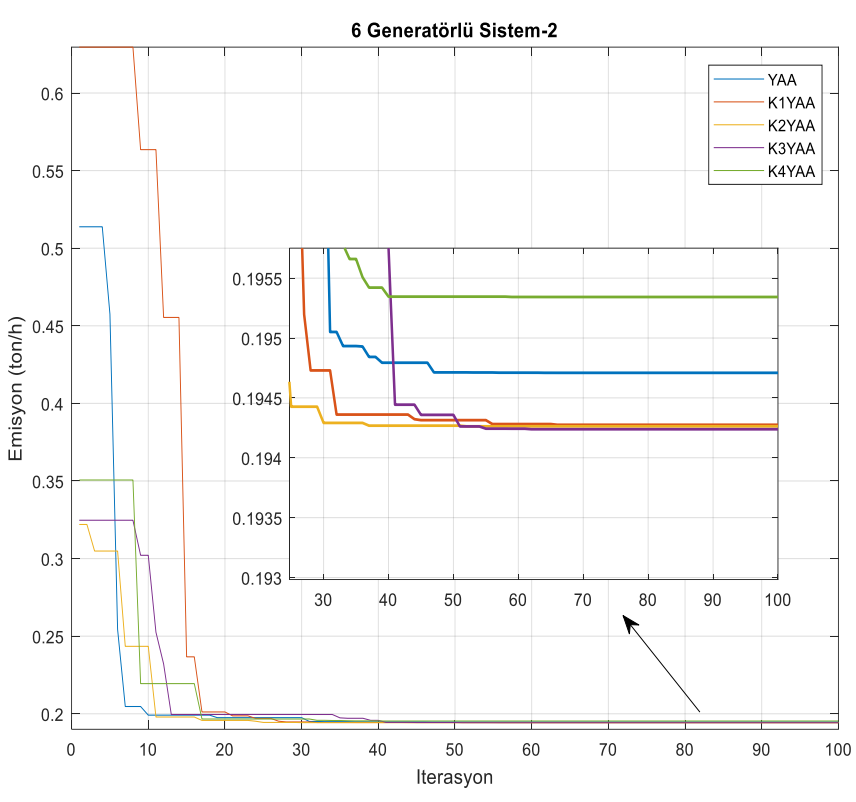

(b)

Şekil 4. Yakıt maliyeti ve emisyon yakınsama eğrileri 6 generatörlü sistem (a) Valf nokta etkisiz test sistemi 2 (b) Emisyonlu test sistemi 2 (Valf nokta etkisiz)

\section{Sonuç ve Tartışma}

Bu çalışmada, son zamanlarda geliştirilen ve literatüre sunulan sezgisel algoritmalardan biri olan yıldırım arama algoritmasının Yıldız ve ark. tarafından kaotik haritalandırma denklemleri kullanılarak iyileștirme yapılan KYAA algoritması ekonomik ve emisyon yük dağıtım probleminin çözümü için iki farklı test sistemine uygulanmıştır. Bu test sistemlerinde dört farklı kaotik haritalandırma yöntemi ve yıldırım arama algoritmasının kendisi kullanılmıştır. Test sistemi kayıplı, kayıpsız, valf nokta etkili, etkisiz koşullar altında minimum toplam yakıt maliyeti ve emisyon değeri $30 \mathrm{kez}$ benzetim çalışması yapılarak elde edilmiştir. Benzetim sonuçlarına göre, kaotik harita yöntemlerinden üçüncüsü (K3YAA) kullanılarak elde edilen sonuçların literatürdeki diğer sonuçlarla karşılaştırıldığında daha iyi ve benzer sonuçlar olduğu görülmüştür. Yıldız ve ark. tarafından literatüre sunulan kaotik yıldırım arama algoritmasının, modern güç sistemleri optimizasyon problemlerinden biri olan ekonomik emisyon yük dağıtımı problemine başarılı bir şekilde uygulandığı gösterilmiştir.

\section{Çıkar Çatışması}

Yazarlar tarafından herhangi bir çıkar çatışması beyan edilmemiştir.

\section{Kaynaklar}

Abido, M.A., 2006. Multiobjective Evolutionary Algorithms for Electric Power Dispatch Problem. IEEE Transactions on Evolutionary Computation, 10(3), 315-329.

Alatas, B., Akin, E., Ozer, A.B., 2009. Chaos Embedded Particle Swarm Optimization Algorithms. Chaos, Solitons \& Fractals, 40(4), 1715-1734.

Alatas, B., 2010. Chaotic Harmony Search Algorithms. Applied Mathematics and Computation, 216, 26872699.

Aydin, D., Özyön, S., Yaşar, C., Liao, T., 2014. Artificial Bee Colony Algorithm with Dynamic Population size to Combined Economic and Emission Dispatch Problem. International Journal of Electrical Power and Energy Systems, 54, 144-153.

Bahrani, L. T. A., Patra, J. C., 2017. Orthogonal PSO Algorithm for Economic Dispatch of Thermal Generating Units under Various Power Constraints in Smart Power Grid. Applied Soft Computing, 58, 401-426.

Basu, M., 2014. Fuel Constrained Economic Emission Dispatch using Nondominated Sorting Genetic Algorithm-II. Energy, 78, 649-664.

Bhattacharjee, K., Bhattacharya, A., Nee Dey, S. H., 2014. Solution of Economic Emission Load Dispatch Problems of Power Systems by Real Coded Chemical Reaction Algorithm. International 
Journal of Electrical Power and Energy Systems, 59, 176-187.

Bingöl, O., Güvenç, U., Duman, S., Paçacl, S., 2017. Stochastic Fractal Search Algorithm with Chaos. International Artificial Intelligence and Data Processing Symposium (IDAP17).

Chatterjee, A., Ghoshal, S.P., Mukherjee, V., 2012. Solution of Combined Economic and Emission Dispatch Problems of Power Systems by an Opposition-Based Harmony Search Algorithm. International Journal of Electrical Power and Energy Systems, 39, 9-20.

Chen, S.D., Chen, J.F., 2003. A Direct Newton-raphson Economic Emission Dispatch. International Journal of Electrical Power \& Energy Systems, 25(5), 411417.

Duman, S., Yorukeren, N., Altas, I.H., 2015. A Novel Modified Hybrid PSOGSA based on Fuzzy Logic for non-convex Economic Dispatch Problem with Valve-point Effect. International Journal of Electrical Power \& Energy Systems, 64, 121-135.

Duman, S., Altaş, I.H., Yörükeren, N., 2014. Çevresel Ekonomik Yük Dağıtımı Probleminin İyileștirilmiş Yerçekimsel Arama Algoritması ile Çözümü. Akıllı Sistemlerde Yenilikler ve Uygulamaları Sempozyumu, 176-181.

Elhameed, M.A., El-Fergany, A.A., 2017. Water Cycle Algorithm-based Economic Dispatcher for Sequential and Simultaneous Objectives Including Practical Constraints. Applied Soft Computing, 58, 145-154.

Frag, A., Al-Baiyat, S., Cheng, T.C., 1995. Economic Load Dispatch Multiobjective Optimization Procedures using Linear Programming Techniques. IEEE Transactions on Power Systems, 10(2), 731-738.

Gandomi, A. H., Yang, X. S., 2014. Chaotic Bat Algorithm. Journal of Computational Science, 5(2), 224-232.

Guvenc, U., Duman, S., Sonmez, Y., Kahraman, H.T., Dosoglu, M.K., in press(2018). Symbiotic Organisms Search Algorithm for Economic Load Dispatch Problem with Valve-point Effect. Scientia Iranica, DOI: 10.24200/SCI.2017.4378.

Hemamalini, S., Simon, S.P., 2008. Emission Constrained Economic Dispatch with Valve-Point Effect using Particle Swarm Optimization. 2008 IEEE Region 10 Conference TENCON 2008.

Hota, P. K., Barisal, A. K., Chakrabarti, R., 2010. Economic Emission Load Dispatch through Fuzzy based Bacterial Foraging Algorithm. International Journal of Electrical Power and Energy Systems, $32,794-803$

Jiang, S., Ji, Z., Shen, Y., 2014. A Novel Hybrid Particle Swarm Optimization and Gravitational Search Algorithm for Solving Economic Emission Load
Dispatch Problems with Various Practical Constraints. International Journal of Electrical Power and Energy Systems, 55, 628-644.

Kavousi-Fard, A., Khosravi, A., 2016. An intelligent $\theta$ Modified Bat Algorithm to solve the Non-convex Economic Dispatch Problem Considering Practical Constraints. International Journal of Electrical Power \& Energy Systems, 82, 189-196.

Kheshti, M., Kang, X., Bie, Z., Jiao, Z., Wang, X., 2017. An Effective Lightning Flash Algorithm Solution to Large Scale Non-convex Economic Dispatch with Valve-point and Multiple Fuel Options on Generation Units. Energy, 129, 1-15.

Lin, C.E., Chen, S.T., Huang, C.L., 1992. A Direct Newtonraphson Economic Dispatch. IEEE Transactions on Power System, 7(3), 1149-1154.

Malik, T. N., Ul Asar, A., Wyne, M. F., Akhtar, S., 2010. A New Hybrid Approach for the Solution of Nonconvex Economic Dispatch Problem with Valve-Point Effects. Electric Power Systems Research, 80, 1128-1136.

Mason, K., Duggan J., Howley, E., 2017. Multi-objective Dynamic Economic Emission Dispatch using Particle Swarm Optimisation Variants. Neurocomputing, 270, 188-197.

Meng, A., Li, J., Yin, H., 2016. An Efficient Crisscross Optimization Solution to Large-scale non-convex Economic Load Dispatch with Multiple Fuel Types and Valve-point Effects. Energy, 113, 1147-1161.

Mirjalili, S., Gandomi, A. H., 2017. Chaotic Gravitational Constants for the Gravitational Search Algorithm. Applied Soft Computing, 53, 407-419.

Nabona, N., Freris, L.L., 1973. Optimisation of Economic Dispatch through Quadratic and Linear Programming. Proceedings of the Institution of Electrical Engineering, 120(5), 574-580.

Naderi, E., Azizivahed, A., Narimani, H., Fathi, M., Narimani, M.R., 2017. A Comprehensive Study of Practical Economic Dispatch Problems by a new Hybrid Evolutionary Algorithm. Applied Soft Computing, 61, 1186-1206.

Pamuk, N., 2013. Dinamik Sistemlerde Kaotik Zaman Dizilerinin Tespiti. Balıkesir Üniversitesi Fen Bilimleri Enstitüsü Dergisi, 15(1), 78-92.

Pandit, N., Tripathi, A., Tapaswi, S., Pandit, M., 2012. An Improved Bacterial Foraging algorithm for Combined Static/Dynamic Environmental Economic Dispatch. Applied Soft Computing, 12, 3500-3513.

Perez-Guerrero, R. E., Cedeno-Maldonado, J. R., 2005. Differential Evolution based Economic Environmental Power Dispatch. Proc. 37th Annual North American Power Symp., 191-197.

Qu, B.Y., Zhu, Y.S., Jiao, Y.C., Wu, M.Y., Suganthan, P.N., Liang, J.J., 2018. A Survey on multi-objective 
Evolutionary Algorithms for the Solution of the Environmental/Economic Dispatch Problems. Swarm and Evolutionary Computation, 38, 1-11.

Secui, D.C., 2015. A New Modified Artificial Bee Colony Algorithm for the Economic Dispatch Problem. Energy Conversion and Management, 89, 43-62.

Shareef, H., Ibrahim, A. A., Mutlag, A. H., 2015. Lightning Search Algorithm. Applied Soft Computing, 36, 315-333.

Shila, C., Ravi, K., 2017. Optimization of Emission/Economic Dispatch using Euclidean Affine Flower Pollination Algorithm (eFPA) and Binary FPA (BFPA) Photovoltaic Generation. Renewable Energy, 107, 550-566.

Tanyıldızı, E., Cigal, T., 2017. Kaotik Haritalı Balina Optimizasyon Algoritmaları. Fırat Üniversitesi Mühendislik Bilimleri Dergisi, 29(1), 309-319.

Yang, D., Liu, Z., Zhou J., 2014. Chaos Optimization Algorithms based on Chaotic Maps with Different Probability Distribution and Search Speed for Global Optimization. Commun Nonlinear Sci Numer Simulat, 19, 1229-1246.

Yașar, C., Özyön, S., 2011. A New Hybrid Approach for Nonconvex Economic Dispatch Problem with Valve-Point Effect. Energy, 35, 5838-5845.

Yıldız, B., Duman, S., Yıldız T.K., 2017. Kaotik Yıldırım Arama Algoritması. IV. International Multidisciplinary Congress of Eurasia (IMCOFE 2017).

Younes, M., Khodja F., Kherfane, R.L., 2014. Multiobjective Economic Emission Dispatch Solution using hybrid FFA (Firefly Algorithm) and Considering Wind Power Penetration. Energy, 67, 595-606.

Zhang, Y., Gong, D. W., Ding, Z., 2012. A Bare-Bones Multi-Objective Particle Swarm Optimization Algorithm for Environmental/Economic Dispatch. Information Sciences, 192, 213-227.

Zhou, J., Wang, C., Li, Y., Wang, P., Li, C., Lu, P., Mo, L., 2017. A Multi-objective Multi-Population Ant Colony Optimization for Economic Emission Dispatch Considering Power System Security. Applied Mathematical Modelling, 45, 684-704

Zou, D., Li, S., Li, Z., Kong, X., 2017. A New Global Particle Swarm Optimization for the Economic Emission Dispatch with or without Transmission Losses. Energy Conversion and Management, 139, 45-70. 